\title{
A Note on the Extent, Operation and Results of Enterprise Zones In the American States
}

\author{
R. Lawson Veasey and \\ Hayward D. Horton
}

\section{Introduction}

Since at least the early 1960s, redistributive politics and demandside economics have formed the basis for most public programs attempting to deal with urban blight. The apparent lack of success of these policies has raised suggestions for new urban program-policies innovations based upon a different economic orientation. Enterprise Zones (EZs) are the supply-side economics alternative for dealing with urban blight.

In this note, we: describe the nature of EZs and briefly their history; present reported cost-benefit effects of EZs as a result of a nationwide survey of state-administered EZ programs; discuss the variety of EZ programs across the states; and suggest the problems of administering the myriad different types of EZs among the states. Finally, we offer several questions posed by this study which will require further investigation regarding the overall impact of EZs on the subnational level.

\section{Historical Overview}

Supply-side economics assumes the fundamental laissez-faire posture that the general good results from private rewards for private actions. Goodman, (1985) defines EZ's:

Enterprise zones are specifically designated, geographically defined areas in which tax and regulatory burdens of all kinds are reduced to provide incentives for private business activity. The idea is to make a specific neighborhood characterized by high unemployment, under used real estate and pervasive property a target for economic development. Government's role is to identify the EZ and, within the zone, reduce taxes and regulations. The private sector's role is to move into the zone to take advantage of the economic opportunities provided by the laissez faire atmosphere of the zone.

Professor Peter Hall introduced the EZ concept in a speech before the Royal Town Planning Society in 1977, Based on his extensive travels in the orient exploring free ports and trade zones (Hall, 1977). The British Parliament, following the suggestions of Hall and Lord 
Howe, established eleven EZs in England's deteriorating business districts. The establishment of the original "zones" in Britain only began the controversy. The EZ concept was introduced in America by Stuart Butler in 1979 in a paper entitled, "Enterprise Zones: A Solution to the Urban Crisis." Butler's arguments so impressed Congressmen Jack Kemp (R-N.Y.) and Robert Garcia (D-N.Y.) that they introduced the first American version of an EZ bill in May, 1980.

The Reagan Administration unsuccessfully pursued national legislation on EZs early in its first term. Meanwhile, a significant number of states-concerned with the immediate problems of economic stagflation-have enacted some form of EZ legislation. Most of these states are one-party Democrat (see Map 1).

The first Kemp-Garcia bill, and its many counterparts, have drawn a great deal of attention nationally. (See Raspberry, 1980; Brimmer, 1980; Butler, 1980; Kemp, 1980; and Hall, 1977) Proponents of the EZ idea, in the states, suggest that "the delays, frustrations and uncertainties of applying for subsidy programs [federal aid] would be replaced by simple and essentially automatic relief from government generated burdens" (Frazier, 1981).

Opponents, suggesting that EZs are an attempted "quick fix" for long-term and complex urban problems, offer severe criticism for the grandiose claims of success for $\mathrm{EZs}$ without benefit of verifiable program results. John Walton provided a thought-provoking criticism of the EZ notion in an early symposium issue of Urban Affairs Quarterly (1982: 17):

Proponents of the legislation [Kemp-Garcia, 1980] argue that it is a remedy for unemployment and urban stagnation. A more critical evaluation indicates that the legislation provides scan benefits for the inner-city poor, but windfall tax advantages for large firms.

Many opponents claim that the passage of the EZ bill might signal a return to laissez faire support for the wealthy, while doing little or nothing for the less fortunate (See Malone, 1982; Goldsmith, 1982; Massey, 1982; Harrison, 1982; Jones, 1982; and Pirie, 1981).

\section{State EZ Programs}

The first state to pass, what was eventually to be called an "enterprise zone" bill was Connecticut in July, 1981. Subsequently, nineteen states have implemented some form of active EZ program and seven other states have passed EZ authorizing legislation (Wolf, 1985).

The diversity and creativity in and among the state programs bears observance (Veasey \& Horton, 1985:5),

The states ... included a variety of incentives in their various program packages. Well over 1,100 zones have been activated since 1982 , with more coming on-line daily. The flurry of economic activity on the subnational level has encouraged many other states to consider passage of similar legislation (New York, Michigan, North Carolina, Hawaii, Wisconsin, West Virginia, 


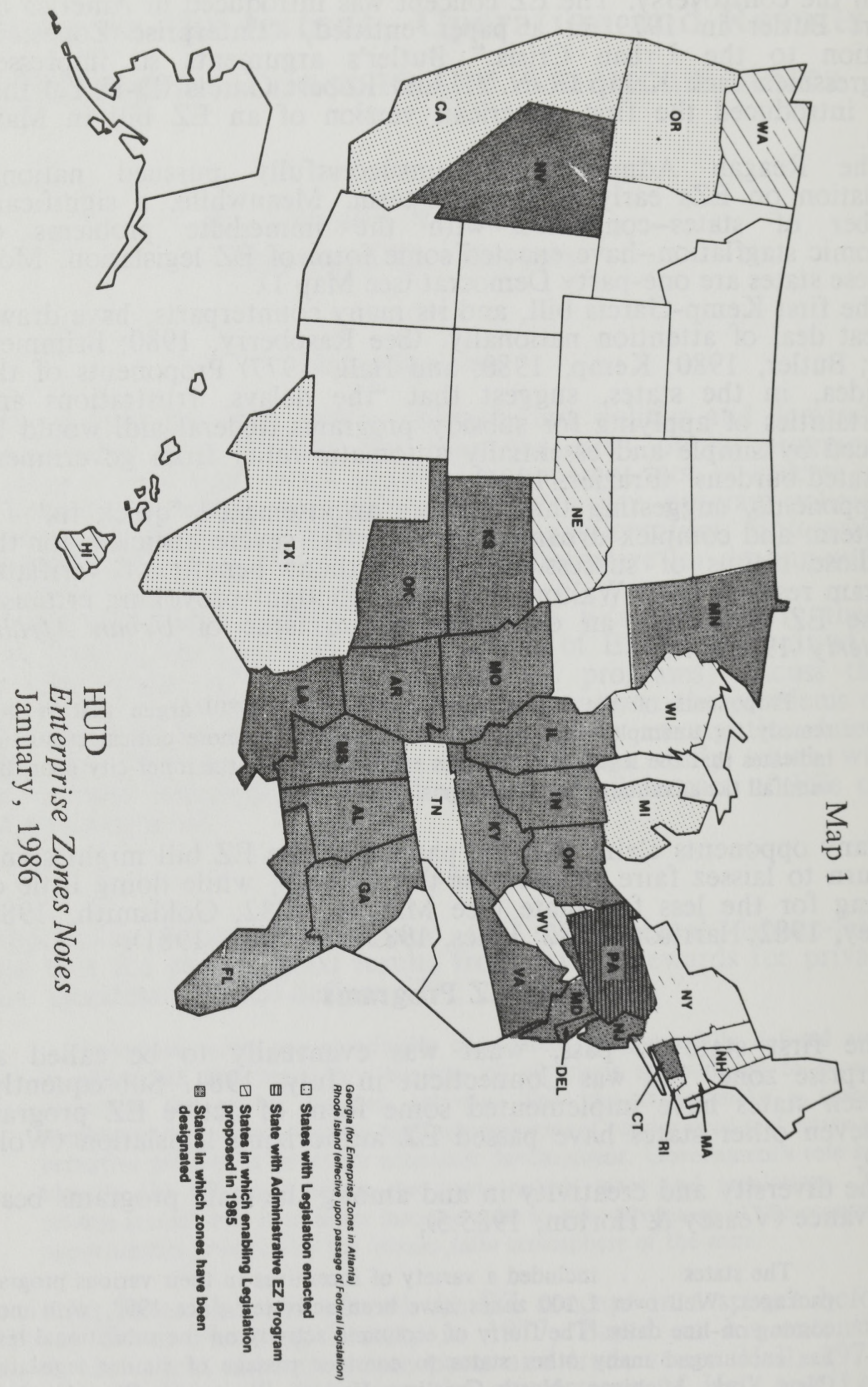


and Colorado.)

Moreover, significant differences exist between the EZ concept and previous federal programs aimed at revitalizing deteriorating communities, such as Haar (1983:4) observes:

REDUCED FEDERAL ROLE - EZs are the theoretical opposite of

urban programs which involved a massive dose of federal assistance and funding into cities.

FUNDING THROUGH TAX BREAKS - past urban programs, such as CDBG or UDAG, have been funded by direct awards.

EMPHASIS ON SMALL BUSINESS - Urban renewal and UDAG have tried to revitalize cities by large-scale downtown developments such as convention centers, hotels and office complexes.

\section{Characterizing State EZ Programs}

Eligibility criteria for entrance into the zone program vary greatly from one state to another. Generally, the zone designation decision is based on the sensitivity to certain requirements, such as: percentage of the population near or below poverty lines (state and federal); availability of municipal support and services; population decline information; specific unemployment date in excess of local, state, or national averages; and other general indicators of deterioration (Herbers, 1985:14).

A diverse range of incentives are being offered by state and local governments to qualify zone participants. 1 Normally, tax incentives have been the focus of most state laws. Property tax reductions, sales tax exemptions on equipment purchases and construction materials, employer credits for selective hiring, and employer income tax credits represent the usual tax breaks in most states and communities. Deregulation relief which has been a central theme of the EZ initiative since that late 1970 s, has not been emphasized by the states. "In fact, given the newness of the program most states appear to have concentrated on tax credits and moratoria, rather than relaxing code enforcement."2

Some proponents of EZs contend that tax relief and deregulation are not enough. "Enterprise zones should be seen as a re-development program," says Dick Cowden, President of the American Association of Enterprise Zones. "If program probably will-fail even if it has substantial incentives without a good understanding of the problems in the zone area" (Fulton, 1986: 3, 20)."

Meanwhile, another condition-the number of EZs within a statehas been changing. 3 Wolf suggests that "an evolution in thinking has occurred ... many of the early state programs . . . allow hundreds of enterprise zones in each state . . Now, the states have cut back the number of zones, of ten choosing 20 or fewer on a competitive basis" (1985:1). This suggests that selective criteria are being employed to deal with the "efficiency, equity, efficacy problem" identified by Clark (1982: 53-71) when she posited that EZs argued for "efficiency 
above equity and efficacy concerns."

Another recent development in the EZ experience is that of incubators. These are "facilities, often rehabilitated buildings that nurture entrepreneurs with a supportive environment, reduced rents, flexible space, shared service, and financial and business development assistance" (Silva:1985,1-2). The incubator tool represents one of many programs that can enhance the EZ concept. Since the EZ program was designed to display a "partnership" attack on economic problems, other federal programs exist to encourage redevelopment: the Small Business Administration (offer capital to inner-city and rural entrepreneurs); the Economic Development Administration (revitalization-oriented public works of benefit to private firms); the Employment and Training Administration (conduct work-experience and work-training programs coordinated under JTPA); Community Development Block Grants (support state and local infrastructure development under the CDBG/States Program and CDBG/Small Cities Program); and Urban Development Action Grants (provide federal funds to leverage private capital to reduce cost of commercial development programs in deteriorating cities. 4

The incubator concept shares with EZs "a set of public goals that include business development, job creation, and revitalization of decaying urban and rural areas (Silva: 1985, 1-2)." An incubator, located within and EZ, offers a number of advantages to potential partners in development, such as: being a focal point for business assistance and job training; to support businesses through critical startup phase with financial assistance and reduced overhead costs; to be a focal point for associations that can organize to participate and plan the development of the EZ; and to provide a community rallying point around a small business anchor within an EZ (Silva: 1985, 1-2).

An incubator-type development that also appears to be stimulating entrepreneurship and revitalization inside EZs is the Research Park. A Research Park is the embodiment of the partnership notion, where private business, government support, university research, and community development efforts can be coordinated to achieve socioeconomic betterment. One such Research Park can be found on the campus of Yale University in New Haven, Connecticut. Although the Research Park preceded the New Haven EZ, the EZ is certainly viewed as an added bonus. Research Parks and incubators are springing up across the nation, many are located in EZs (Goodman: 27).

\section{Verification of EZ Results}

David Bocck, poses, among other questions, the problem of verification of EZ program claims (1984:71-173):

There is no genuine consensus that enterprise zones will both revitalize distressed areas and create jobs for the structurally unemployed. . . Some federal programs should be expanded, some substantially modified, some resurrected, and some abandoned. There remains room for experimentation ... enterprise zones [are] an experiment. 
Bocck's concern with verification of EZ program results is one that the states are currently dealing with. Professor Earl Jones, of the University of Illinois and a critic of "overselling", stated that EZs "may not, at this point, be stimulating revitalization... however, EZs have multiple objectives, and it is difficult to reach any firm, comprehensive conclusions regarding program effectiveness" (1985:294295).

In an early article, Jones offered a few preliminary observations concerning EZs and how they might be improved to address some shortcomings (1983:57-68):

The enterprise zone concept and state programs present a unique approach to comprehensive neighborhood revitalization. However, state programs do not provide grass-roots organization and equity stake in zone development or a meaningful role in zone decision making. To achieve a more equitable distribution of public resources, provide jobs and revitalize distressed neighborhoods, EZ planning must include provisions for job training, venture capital for small and minority firms, anti-displacement policies and meaningful citizen participation.

Jones' comments were made early on in the EZ experience, similar to the observations made by Mier and Gelzer (see Table 1). The latter authors (1982:39-52) suggest seven elements of targeted development that might be applied and, implicitly, improve current EZ strategies. Further, they indicate that the Florida and Connecticut EZ programs contain elements of that strategy along with concepts gained from state developement lessons learned in the 1960 s and $1970 \mathrm{~s} .5$ We compare those seven elements to possible connections contained in State EZ programs, as well as existing federal support programs.

Table 1 compares the improvements suggested by Mier and Gelzer in 1982 to program innovations and alterations that are currently being implemented in many of the state EZ programs. Much of the criticism levied at the EZ concept was directed at the various federal proposals which eventually failed. Subsequently, the states have adjusted their programs to be more sensitive to those earlier criticisms. The tabular comparison indicates two important differences between federal and state EZ proposals: (1) that state EZ programs appear to be much more dynamic than the oft-failed proposals on the national level; and (2) that the states have departed drastically from more laissez-faire provisions which were found to be so objectionable in the Congress. Verifications are found in state EZ legislation, whether or not those regulations are being enforced remains to be discovered.

Obviously, claims made by proponents indicative of a move toward equalitative programs run in direct contrast to the laissez-faire philosophy on which the EZ concept was constructed. Whether or not these changes are implemented remain to be seen, but stated requirements (as listed in Table 1) at least pay lip service to the criticisms posed by opponents.

A number of claims have been made concerning state EZs with regard to economic development, especially the number of jobs 


\section{TABLE 1}

Mier and Gelzer Program

(1) partnerships in developmentcombining business, civil, and labor interest.

(2) professional capability - aid in based development by providing managerial support.

(3) guality of life - upgrade public and physical infrastructure.

(4) capital pool creation - to assist small business development.

(5) human resource enhancement -place emphasis on education and training

(OJT) .

(6) encourage stake in the wealth

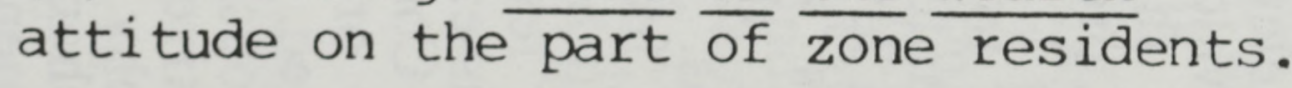

(7) bargaining to exist in the marketplace - include the commity, labor, and public sector in the process.

\section{Existing State/Federal Comparables}

(1) Incubators, Research Park, Industrial Development Agencies with Community Development tie-in.

(2) State and Local Administrative aid, plus federal support (DOE, HUD, HHS, etc.)

(3) 17 states have infrastructure support + federal UDAG, CDBG, SCDBG, etc.

(4) 11 states have bond support, 8 have capital support, + public/ private partnerships.

(5) State/Federal partnerships in JTPA + many states require hiring zone residents.

(6) connect incentives to high unemployment, population decline data, and UDAG qualifications.

(7) states reserve EZ designation right + community support and commitment. 
created or saved; the amount of economic expansion occurring; the low costs to the states of incentives; the high yield of investment dollars per dollar of incentive; and general claims of revitalization and economic growth. State EZ coordinators, though certainly not unbiased, may provide the best data available addressing the redevelopment aspect with regard to cost/benefit analysis.

\section{Survey of EZ Coordinators}

Twenty-five of twenty-six state EZ coodinators were surveyed by phone from February 5-18, 1986. In the state of Tennessee the EZ coodinator was unavailable for comment, subsequent discussion was held with an administrative assistant. Also, economic development officials were contacted in the states of New York and Michigan since they are currently involved in the consideration of EZ legislation (their comments were not included in the results of the paper). Secondary source materials were accessed, such as: annual reports, HUD publications, National Association of State Development Agencies (NASDA) reports and journal articles. Mailed questionaires were received from thirteen of twenty-six State Coordinators. Followup phone interviews were successful in surveying all programs.

\section{Program Description}

One of the most salient aspects of the Enterprise Zone concept is the variability that exists between the state programs. In part, this is not surprising. It is in the interest of each state to have a program that is suited to its specific socioeconomic, political, ecological and demographic conditions. However, because of the uniqueness and diversity of the respective state programs, the task of making comparisons becomes all the more difficult. For instance, there are vast differences in the number of zones that have been created by states. Oregon will have 10 enterprise zones (EZs) by the end of 1986 but Arkansas already has 272 EZs; Illinois has 48 while Alabama has 2 EZs. These differences in the number of designated zones are important because they underscore the disparity in budgets, and time allocation for the coordinators of the respective states.

On the other hand, despite the variability in the state programs, a few important, general patterns do emerge. First, the primary emphasis of the EZs programs is the creation of jobs. Approximately $67 \%$ of the state EZ coordinators ranked job creation first over industrial/economic growth and revitalization as the major goal of their respective programs. Secondly, size of place does not appear to be a determining factor in zone designation. Well over half of the state coordinators indicated that rural areas as well as large and small cities were targeted by their programs. Likewise, there was some consistency on flexibility in terms of the type of economic activity encouraged in the zones and the size of the businesses in which the zones were designed to attract. One hundred percent of the coordinators' programs were equally as likely to focus on industrial/heavy manufacturing, light manufacturing and commerical/retail firms. Size of these firms did not appear to be 
important to $78 \%$ of the coordinators.

\section{Coordinator Responsibilities}

One of the more interesting findings here is the relatively loose and informal relationships that exist between the state and local EZ coordinators. Approximately 56\% of the coordinators indicated that those relationships were informal, while $100 \%$ of the EZ coordinators reported that they do not hire local coordinators or collect sociodemographic data on zone workers. Moreover, whereas $71 \%$ of the state coordinators are not responsible for training the local coordinators. One possible implication of this type of "looseness" is the structural relationship between state and local coordinator. Considering that the local coordinator has more direct involvement in specific zone, and theoretically a better grasp of potential problems, this relationship might be perceived as advantageous. However, it also implies that the state coordinator does not have the resources' (budget and time) to effectively administrate the zone and has therefore relinquished control to the local coordinators. If this is in fact the case, then not only will there likely be considerable intrastate variability in EZ activity, but the state coordinator may be relatively oblivious to the actual nature of that activity. Consequently, not only would interstate comparisons be increasingly difficult, but the evaluation of each state's program would be a monumental task as well.

\section{Sociodemographic Characteristics of Coordinators}

An examination of the sociodemographic characteristics of the state coordinators yields expected results. Most are male (86\%), middle aged $(71 \%)$, married $(71 \%)$ and white $(86 \%)$. All of the coordinators are college educated and $71 \%$ have graduate degrees. Further, $57 \%$ are in the 30-40 thousand dollar annual income category. To reiterate, these findings are not unexpected. Generally, professional and/or administrative positions are held by white, middle class, middle-aged males in American society. Consequently, not only is an understanding of the sociodemographic characteristics of the state coordinators relevant to an analysis of the state EZ programs, it is absolutely necessary for the subsequent evaluations of the zones that are certain to come, because person's with these characteristics possess the administrative skills and network connections so important to the ultimate success or failure of the program.

\section{Effectiveness of EZ's}

The review of current literature suggests that the EZ initiative claims a substantial amount of success on the state and local levels. As of September, 1985, there "are more than 1,300 zones in over 600 jurisdictions," stated Lee L. Verstanding (1985:1), former Undersecretary of HUD. Further, Verstanding (1985: 1) stated:

A conservative estimate of the economic impact of zones is seen in the 
Table 2: State Enterprise Zone Activity

No. of EZs (Date) Jobs Created/Saved Investment Benefit Cost

\begin{tabular}{|c|c|c|c|c|c|}
\hline ALABAMA & 2 & $9 / 85$ & & & \\
\hline ARKANSAS & 272 & $12 / 85$ & 6,580 & $\$ 452 \mathrm{mil}$. & \\
\hline CALIFORNIA & 13 & Design in Proces & & & \\
\hline CONNECTICUT & 6 & $8 / 85$ & $4,219 / 4,324$ & $\$ 135 \mathrm{mil}$. & \\
\hline DELEWARE & 48 & $2 / 86$ & & & \\
\hline FLORIDA & $136 / 2 \varnothing$ & $1 / 1 / 86$ & 21,742 & & $\$ 8 \mathrm{mil}$. \\
\hline GEORGIA & 3 & $9 / 85$ & $1,327 / 3,000$ & s $33 \mathrm{mil}$. & \\
\hline ILLINOIS & 32 & $11 / 85$ & $3,555 / 5,368$ & $154.5 \mathrm{mil}$ & \\
\hline INDIANA & 10 & $9 / 85$ & $2,529 / 1,229$ & $186 \mathrm{mil}$ & \\
\hline KANSAS & 123 & $12 / 85$ & $668 / 2,000$ & 1.313 bil. & \\
\hline KENTUCKY & 6 & $9 / 85$ & 1,542 & & \\
\hline LOUISIANA & 703 & $9 / 85$ & 10,523 & $652.7 \mathrm{mil}$. & \\
\hline MARYLAND & 11 & $8 / 85$ & 49 & $3.8 \mathrm{mil}$. & $\$ 19 \theta, \varnothing \varnothing \theta$ \\
\hline MINNESOTA & 11 & $9 / 85$ & $116 / 3,532$ & $50 \mathrm{mil}$. & $1.8 \mathrm{mil}$. \\
\hline MISSISSIPPI & 10 & $9 / 85$ & & & \\
\hline MISSOURI & 24 & $9 / 85$ & 1,400 & $16 \mathrm{mil}$. & \\
\hline NEVADA & 2 & $9 / 85$ & & & \\
\hline NEW JERSEY & 5 & $9 / 85$ & 637 & & \\
\hline OHIO & 30 & $2 / 86$ & $1,220 / 3,900$ & & \\
\hline OKLAHOMA & 14 & $2 / 86$ & & & \\
\hline OREGON & 10 & Design. in Proce & ess & & \\
\hline PENNSYLVANIA & 15 & $2 / 86$ & 4,956 & $198 \mathrm{mil}$. & $\$ 5 \mathrm{mil}$. \\
\hline RHODE ISLAND & Wait & iting for Federal & Action & & \\
\hline TENNESSEE & Wait & iting for Federal & Action & & \\
\hline TEXAS & Awai & ating Local Desig & gn. & & \\
\hline VIRGINIA & 12 & $5 / 85$ & $89 / 170$ & & \\
\hline Michigan & 1 & (Pilot Program in & n City of Benton & Harbor) & \\
\hline
\end{tabular}

Source: Veasey-Horton Surveys 
results of an analysis of those states where zones have been in operation. Over 75,000 jobs have been created or retained and more than 2.5 billion of capital investment has been realized.

Our survey indicates than an estimated 84,705 jobs have been created or saved with $\$ 3,194$ billion in new investment occurring. Table 2 represents a report by various State EZ Program Coordinators, most of which are unconfirmed.

Verification of investment dollars as well as the number of jobs created/saved is subject to significant speculation, but a number of states have attempted to confirm this data through the certification of benefits applied for by the industry. For example, the State of Arkansas has designated 272 zones including 129 businesses. Accrued investment benefits have exceeded $\$ 452$ million and has created an estimated6,580 new jobs. A total of 1,280 jobs have been verified through audit of state corporate income tax data as reviewed by the EZ program under the Arkansas industrial Development Commission, as well as the Arkansas Department of Finance and Administration. 6 Arkansas, Pennsylvania, Oregon, California, and the recent revision of the Florida EZ programs represent a sample of the states who have or who are seeking to enhance their reporting, monitoring and auditing features of their respective programs.

Beyond the review conducted by each state's development agency, many states, like Arkansas, have their EZ program results reviewed by the state auditing department. This independent review suggests a much more reliable source of information since many state auditing departments are independent of the economic development agencies.

\section{Conclusions}

In this study, some preliminary evidence was examined in an effort to present an objective description and analysis of the EZ phenomenon. It was found that the predominant characteristic of the respective state programs was a high degree of diversity. The states differed significantly in the number of zones created and activated, as well as the degree of financial and human resources allocated for implementation of the respective programs. Moreover, most EZ programs placed a primary emphasis on the creation of jobs and were designed to attract a wide array of business and industry in both urban and rural areas. Their methods to effect this tended to emphasize tax credits, but not state deregulation. The nature of the relationship between state and local EZ coordinators is loose and informal in most programs. It was argued that such a structure has both advantages and disadvantages. Finally, an argument was raised in terms of the significance of indicating the sociodemographic characteristics of the state EZ coordinators: middle-class white males predominate.

With regard to the claims of EZ results, preliminary review of survey data suggests that state sponsored EZ programs may be creating/saving jobs and stimulating economic development. Verifiable results are in short supply, though state legislatures seem to be adjusting EZ programs where the costs of incentives and the revenues generated by the implementation of EZ programs can be 


\section{R. Lawson Veasey and Hayward D. Horton}

more readily obtained. (See Table 1). Economic activity seems to be increasing, although where the benefits are directed and who is paying the cost is unclear. All of the benefits of EZs have not been identified or evaluated.

Suffice it to say, the EZ phenomenon will merit considerable review to determine if stated goals are achieved. EZ program costs data seem to be more readily available than data on benefits. Possibly, future research might be directed toward the development of verifiable benefits-if they exist. Verification of program results will be made more difficult by the apparent changing of $\mathrm{EZ}$ objectives from the original federal proposal to extant state EZ programs.

\section{Endnotes}

1. See Wolf's Enterprise Zone Gazette and HUD's Enterprise Zone Updates and Enterprise Zone Notes for progressive updates on state activities.

2. Authors quoting Michael A. Wolf and Dick Cowden (American Association of Enterprise Zones) at the National Association of State Development Agencies; Enterprise Zone Task Force Roundtable, October 3-4, 1985, in Hartford, Connecticut. NASDA, in their State Enterprise Zone Roundup of September, 1985, indicates that 16 of the 26 current programs offer sales and use taxes, 15 offer income tax reductions, 13 include tax credits for employing EZ residents, and 10 offer property tax adjustments.

3. Fulton indicates that Louisiana has more than 600 , Arkansas more than 200 , and Florida, more than 100 EZs.

4. See John Topping, Sourcebook on Enterprise Zones (Washington, D.C.: Sabre Foundation, 1980.)

5. Citation reports on the work of the Washington based Urban Development Task Force as discussed by Humberger, Mier, and Williams An Alternative to Enterprise Zones: Guidelines For A State Development Act (Washington, D.C,: The Resource Group for Community Development, 1982.)

6. Telephone update of mailed survey. Information supplied by Mr. Oscar Rodriguez, Director of the Arkansas EZ Program, Feb. 13, 1986.

\section{References}

Bocck, D. (1984). "The Enterprise Zone Debate," The Urban Lawyer. Winter. pp. 7173.

Brimmer, A. (1980). "Can Enterprise Zones Work?" Black Enterprise. 3/11. p. 71.

Butler, S.M. (1979). Enterprise Zones: A Solution to the Urban Crisis. Washington, D. C. : Heritage Foundation.

(1980). Enterprise Zones: Pioneering in the Central City. Washington, D.C.: Heritage Foundation. 


\section{Operation and Results of Enterprise Zones}

Clarke, S. (1982). "Enterprise Zones: Seeking the Urban Nexus," Urban Affairs Quarterly. Vol. 18, No. 1. pp. 53-71.

Frazier, M. (Ed.) (1981). Sourcebook on Enterprise Zones. Washington, D. C.: Sabre Foundation.

Fulton, W. (1986). "States Take Initiative," City and State. January. pp. 3 and 20.

Goodman, Roy M. (1985). Rebuilding Our Cities: The Case For Enterprise Zones. The State legislature of New York: Report by Legislative Commission on Public Private Partnerships.

Goldsmith, W. (1982). "Enterprise Zones: If They Work We're in Trouble," International Journal of Urban and Regional Research 6, pp. 435-442. See the entire issue for criticism expressed by Harrison, Massey, et al.

Haar, C., et al. (1983). "Urban Enterprise Zones: Inner City Panacea or Supply-side Showpiece?" Lincoln Institute of Land Policy. HUD reprint (HUD-CPD-755R), p. 4.

Hall, P. (1977). "Greenfields and Gray Areas," Speech before the Royal Town Planning Institute, July 15.

Herbers, J. (1985). "Local Incentives Draw Industry to Poor Zones," New York Times. 7/28. p. Y14.

Jones, B. (1982). The Geography of Enterprise Zones: A Critical Analysis," Economic Geography. October. pp. 329-342.

Jones E. (1985). Housing and Development Reporter. "Academic-Urban Experts Examine U.S. and British Enterprise Zones." Vol. 13, No. 16. pp. 294-295.

(1983). "Enterprise Zones: Preliminary Observations," Journal of Voluntary Action Research. Vol. 12, No. 3, pp. 57-68.

Kemp, J. (1980). "Greenlining Urban America: Enterprise Zones for Economic Growth," Commentary. July. pp. 3-6.

Malone, Janet H. (1982). "The Questionable Promise of Enterprise Zones: Lessons from England and Italy," Urban Affairs Quarterly. Vol. 18, No. 1, pp. 19-30.

Pirie, M. (1981). “A Short History of Enterprise Zones," National Review. 1/23. pp. 2629.

Raspberry, W. (1980). "Urban Enterprise," The Washington Post. Washington, D.C. $5 / 9$.

Silva, S. (1985). "Enterprise Incubators," Enterprise Zone Notes. Washington, D. C. ; HUD.

Veasey, R. L. and Horton, H. (1985). "States Initiate Enterprise Zone Programs," SIAM Intergovernmental News. Vol. 9, No. 1. p. 5. 
Verstanding, L. (1985). "Zone Initiatives In The State," Enterprise Zone Notes. Washington, D. C. : HUD.

Walton, J. (1982). "Cities and Jobs and Politics," Urban Affairs Quarterly. Vol. 18, No. 1. pp. $5-17$.

Wolf, M. (1985). Enterprise Zone Gazette. Oklahoma City: Oklahoma City School of Law. Winter. 